\title{
Research
}

\section{Emergency hospital admissions for asthma and access to primary care:}

\author{
cross-sectional analysis
}

\begin{abstract}
\section{Background}

Access to general practices may be an important determinant of emergency admissions for asthma, as early treatment of exacerbations has been shown to prevent deterioration.

\section{Aim}

To determine whether access to primary care is associated with emergency admissions for asthma.
\end{abstract}

\section{Design and setting}

Cross-sectional analysis of data from English practices in 2010-2011.

\section{Method}

Negative binomial regression was used to explore the associations between emergency admissions for asthma and seven measures of patientreported access to general practice services taken from the GP Patient Survey, controlled for the characteristics of practice populations Incidence rate ratios (IRR) were calculated for each association.

\section{Results}

In total 7806 (95\%) of practices had data for all variables. There were 3134106 patients with asthma, and there were 55570 emergency admissions with asthma. Admission rates were lower in practices with a higher composite access score ladjusted IRR for $10 \%$ change in variable $0.679,95 \% \mathrm{Cl}=0.665$ to 0.708 ) Admissions were higher in those practices with higher proportions of the practice population who were white, and in practices with lower performance in the Quality and Outcomes Framework indicator 'asthma review in past 15 months' (Asthma 6). Assuming these associations were causal, a higher access score of $10 \%$ was associated with a decrease of 17837 admissions per year for these practices.

\section{Conclusion}

Practices with higher patient-reported access had lower rates of emergency admissions for asthma. Policymakers should consider improving access to primary care as one potential way to help prevent emergency hospital admissions for asthma.

\section{Keywords}

asthma; emergency admissions; healthcare quality, access, and evaluation; primary care.

\section{INTRODUCTION}

Asthma is a chronic inflammatory condition of the airways with variable reversible obstruction caused by bronchial hyper-reactivity. The main symptoms are breathlessness, wheeze, chest tightness, and cough. It has a prevalence of $6 \%$ in England and is largely managed in primary care. ${ }^{1}$ Despite the availability of management guidelines, ${ }^{2}$ quality targets with financial incentives in the Quality and Outcomes Framework lQOF; the pay for performance scheme set out in the National Contract for Primary Care in the UK), and effective treatments, ${ }^{3}$ there remains significant morbidity and mortality from acute exacerbations of asthma. ${ }^{4}$ Hospital admissions for asthma are included as an 'ambulatory care sensitive condition' internationally, which are conditions in which hospital admission is thought to be largely preventable.,6 Each year in Western Europe $25 \%$ of patients with asthma require unscheduled emergency health care, 10\% require an emergency department visit, and $7 \%$ are hospitalised because of their condition. ${ }^{7}$ Reduced continuity of care was associated with increased emergency hospital admission in three studies identified in a recent systematic review. ${ }^{8}$ Up to $90 \%$ of deaths and $70 \%$ of emergency admissions with asthma are associated with potentially preventable factors. ${ }^{9}$ Appropriate treatment of acute exacerbations is known to reduce hospital admissions and deaths, and is recommended as part of patient

R Fleetcroft, MD, MRCP, FRCGP, honorary senior fellow; A Martin, medical student; E Coombes, PhD, senior research associate; J Ford, MBChB, NIHR doctoral fellow in public health; N Steel, MBChB, $\mathrm{PhD}$, reader in primary care, Norwich Medical

School, Norwich. M Noble, MB BChir, GP, Acle Medical Partnership, Acle, Norfolk.

Address for correspondence

Robert Fleetcroft, Norwich Medical School, Faculty of Medicine and Health Sciences, University of East self-management plans. ${ }^{2,10}$ For patients at greatest risk of an asthma attack, nurse-led interventions, emphasising education and self-management plans, have been shown to increase the time to first attendance for unscheduled care for asthma. ${ }^{1}$

Population factors are associated with avoidable admissions for asthma, and it is plausible that accessing primary care services may also be an important factor. A recent National Review of Asthma Deaths (NRAD) has shown that poor access to care and poor adherence with medication were contributory factors in asthma mortality. ${ }^{4}$ Two English studies that targeted asthma patients at high risk of adverse outcomes by flagging the medical record and training staff to improve access have reported reduced hospital admission, as well as improved quality of care. ${ }^{12,13}$ Increased emergency asthma admissions have been reported to be associated with decreased access to health care in North Carolina in the US. ${ }^{14}$

Data are collected annually on seven measures of patient access to primary care for each general practice in the UK by the GP Patient Survey. ${ }^{15}$ This is one of the largest surveys of patients registered to receive primary health care, sampling 5 million patients in 2010.15,16 These data are collected by surveying patients from every practice, asking questions including the ease of making urgent and routine appointments, getting through on the telephone, the helpfulness of receptionists,
Anglia, Norwich NR4 7TJ, UK.

E-mail: robert.fleetcroftanhs.net

Submitted: 27 July 2015; Editor's response: 23 November 2015; final acceptance: 27 January 2016.

\section{@British Journal of General Practice}

This is the full-length article (published online 21 Jun 2016) of an abridged version published in print. Cite this version as: $\mathbf{B r} \mathbf{J}$ Gen Pract 2016; DOI: 10.3399/bjgp16X686089 


\section{How this fits in}

Asthma is a common condition that occasionally can become life-threatening and lead to emergency hospital admission. Early treatment of exacerbations has been shown to reduce emergency hospital admission rates. This study has reported an association between higher rates of hospital admission for asthma and poorer access to primary care practices. This study adds to the growing literature reporting an association between better access to primary care and lower rates of emergency admissions for a number of conditions.

being overheard in reception, and seeing their preferred doctor (Appendix 1). The data have been combined into a composite access indicator by the Picker Institute, and used as an indicator of access to primary care. The advantages of using composite indicators include that they offer a more rounded assessment of performance and present the big picture in a way that is easy to understand. ${ }^{17}$ Research using individual questions from the GP Patient Survey has demonstrated an association between improved measures of access to primary care services and a decrease in hospital admission rates for chronic obstructive pulmonary disease, heart failure, diabetes, stroke, cancer, and epilepsy. ${ }^{18-23}$ Similar associations have been seen for access to primary care services and accident and emergency department use, and higher use of out-of-hours services. ${ }^{24,25}$ It is hypothesised that better access to primary care is associated with reduced emergency admission rates for asthma.

\section{METHOD}

A cross-sectional analysis was performed on data from general practices in England for the year 2010-2011. All data (with the exception of data on ethnic groupl were obtained from the Health and Social Care Information Centre, for the year April 2010 to March 2011.26 Data on ethnic group were obtained from the Eastern Region Public Health Observatory for 2007-2008. ${ }^{27}$ The dependent variable was the rate of emergency admissions for asthma per 1000 patients on the asthma register, for each general practice. The codes for emergency admission were the PBR tariff 21, 22, 23, 24 , 28; the ICD-10 primary diagnoses codes for asthma were J45-J46.

The main independent variables were the access scores for each practice taken from the GP Patient Survey, which were used as a proxy measure for accessibility of general practices. Data on patient access to general practice have been developed by Ipsos MORI for the GP Patient Survey, in conjunction with the Picker Institute. ${ }^{28}$ In 2010-2011 there were seven questions relating to patient access to their surgery (Appendix 1). The patient access indicators were based on a survey of $10 \%$ of the general practice population with a median response rate of $41 \%$ at the practice level (interquartile range 32-47\%). These access questions have been combined by the Picker Institute to form a composite access score for each practice. Four out of seven of these access questions were found to have construct validity when compared with simulated patient calls to the practice Ifinding it easy to get through on the phone, can get an appointment within 2 days, finding the receptionists helpful, and can see preferred doctor)..$^{29}$ One question was found not to have construct validity lgetting an appointment with a doctor more than 2 full weekdays in advance), and a further two questions were not tested (can other patients overhear what you say to the receptionist, ease of getting appointment with practice nurse). ${ }^{29}$ Several of these access questions have been used in other research as proxies for markers of patient access to surgery, although the composite access score has not yet been used as a research tool. ${ }^{18-24}$

Further independent variables that have been shown to be associated with variation in practice-level performance in previous studies in English primary care were identified. These were: the size of the practice measured in numbers of patients in 2010; and the GP Practice Index of Multiple Deprivation (IMD 2010, rank), which is estimated by taking a weighted average of the IMD scores for each Lower Super Output Area (LSOA) in which a given practice has registrations. The IMD is an overall measure of multiple deprivation experienced by people living in an area and is constructed from combining 38 indicators across seven distinct domains of deprivation..$^{30}$ Additional independent variables included the indicator performance taken from the QOF in 'Asthma 6' (the percentage of patients with asthma who have had an asthma review in the previous 15 months) and 'Asthma 8' (the percentage of patients aged $\geq 8$ years diagnosed as having asthma from measures of variability or reversibility); the rank of the proportion of the practice population that were white; the average age of the practice population; 


\section{Table 1. Practice-level descriptive statistics}

\begin{tabular}{|c|c|c|c|c|c|}
\hline & $n$ & $\begin{array}{c}\text { Mean } \\
\text { (min-max) }\end{array}$ & $\begin{array}{c}25 \% \\
\text { quartile }\end{array}$ & $\begin{array}{c}50 \% \\
\text { quartile }\end{array}$ & $\begin{array}{c}\mathbf{7 5 \%} \\
\text { quartile }\end{array}$ \\
\hline Practice list size & 7806 & 6680 (253-40228) & 3386 & 5865 & 9164 \\
\hline Number of patients with asthma & 7806 & $401.50(6-2280)$ & 190 & 344 & 561 \\
\hline Number of admissions with asthma & 7806 & $7.12(0-63)$ & 3 & 6 & 10 \\
\hline Admissions per 1000 asthma patients & 7806 & $20.02(0-700)$ & 9.00 & 16.00 & 26.00 \\
\hline Composite access score, \% & 7806 & 71.97 (38.31-96.18) & 66.38 & 72.07 & 77.82 \\
\hline $\begin{array}{l}\text { Q1: How easy have you found getting } \\
\text { through on the phone? } \%\end{array}$ & 7806 & $69.30(16-99)$ & 60.48 & 71.88 & 80.47 \\
\hline $\begin{array}{l}\text { Q2: Are you able to see doctor } \\
\text { in } 2 \text { days? } \%\end{array}$ & 7806 & $80.01(25-100)$ & 72.79 & 81.14 & 88.58 \\
\hline Q3: Are you able to book ahead? \% & 7806 & $71.48(0-100)$ & 61.46 & 72.71 & 82.63 \\
\hline $\begin{array}{l}\text { Q4: Can patients overhear in } \\
\text { reception? \% }\end{array}$ & 7806 & $85.15(2-100)$ & 81.24 & 86.91 & 91.09 \\
\hline Q5: How helpful are receptionists? \% & 7806 & $92.21(53-100)$ & 89.47 & 93.24 & 96.19 \\
\hline $\begin{array}{l}\text { Q6: See their preferred doctor always, } \\
\text { almost always, or a lot of the time, \% }\end{array}$ & 7806 & $71.45(15-100)$ & 61.36 & 72.95 & 82.81 \\
\hline $\begin{array}{l}\text { Q7: Ease getting appointment with } \\
\text { practice nurse, } \%\end{array}$ & 7806 & $66.36(4-96)$ & 60.30 & 67.28 & 73.45 \\
\hline Average age, years & 7806 & $39.50(25-80)$ & 36.84 & 39.93 & 42.34 \\
\hline White, \% & 7806 & $80.11(0-100)$ & 71.66 & 92.61 & 97.27 \\
\hline IMD 2010 & 7806 & $23.92(3-68)$ & 13.72 & 22.09 & 32.35 \\
\hline Achievement Asthma indicator 6, \% & 7806 & $80(0-100)$ & 74 & 78 & 84 \\
\hline Achievement Asthma indicator 8, \% & 7806 & $88(0-100)$ & 84 & 88 & 93 \\
\hline Distance to nearest hospital, km & 7806 & $9.27(0.5-98.93)$ & 3.49 & 6.07 & 12.74 \\
\hline
\end{tabular}

Figure 1. Scatterplot of emergency admissions for asthma and composite scores for practices.

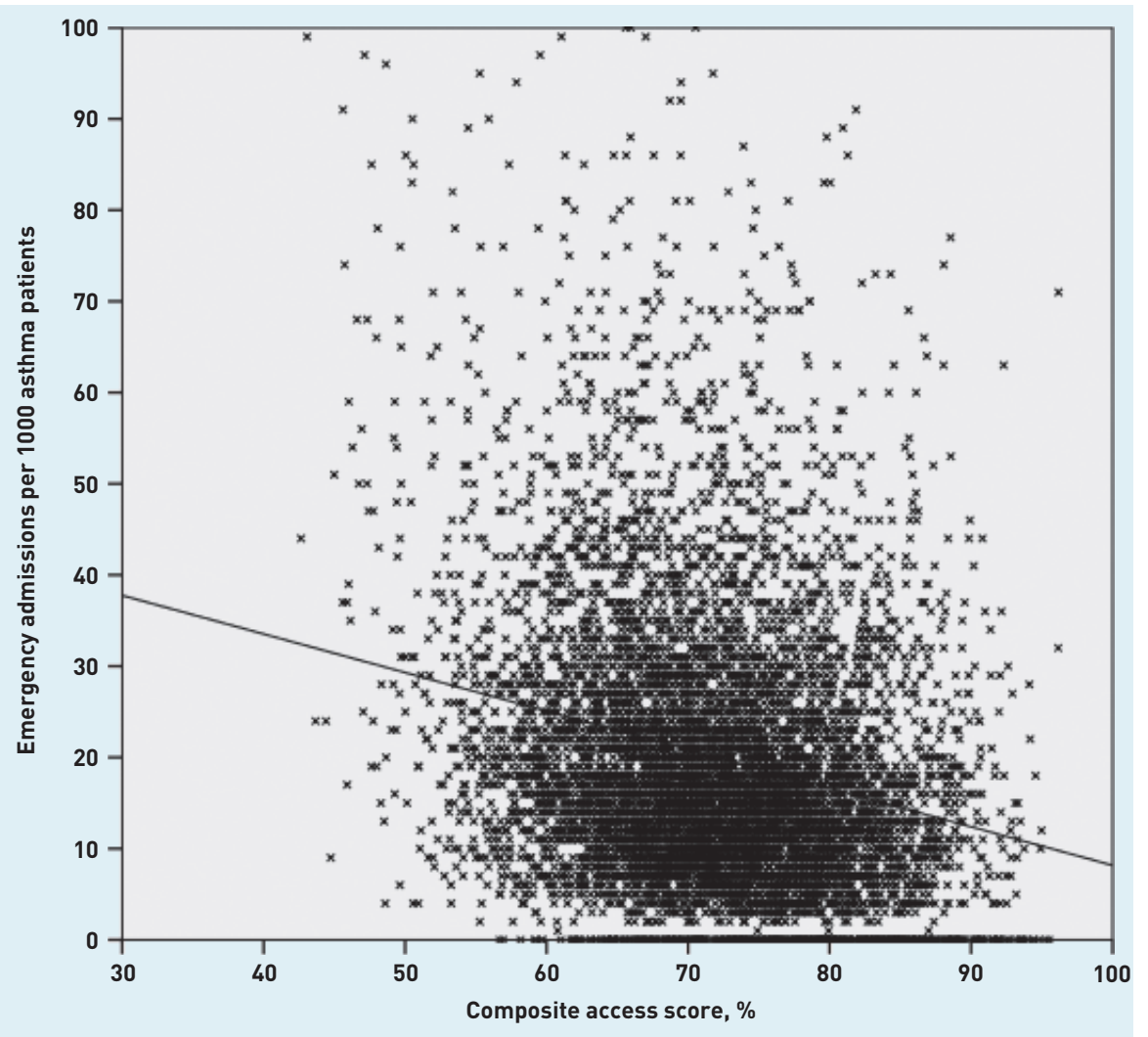

the percentage of the practice population who were female; and the distance of the practice from the nearest hospital that takes emergency asthma admissions. This distance was calculated using the Geographical Information System (GIS) package ArcGIS version 10.1. To compute this, a digital representation of the road network was constructed using Ordnance Survey Meridian data and network routing algorithms were used in the GIS to identify the most direct route along the road network from each practice to the nearest hospital, and to calculate the total distance, measured in kilometres, for that route. All calculations assumed car travel.

Data were analysed in SPSS (version 22) and Stata (version 13). Of the total of 8236 practices, five were excluded as they were closest to a Scottish hospital and no admissions data were available. Likewise seven practices were excluded as they were nearest to a Welsh hospital, and one practice was excluded as it was an island practice. A scatterplot of the main variables lemergency admission rates for asthma and access composite scores) suggested a linear association. A rank of IMD and rank of the proportion of the practice population that were white were used because these data were not normally distributed. Tests for variance inflation factors suggest that there was no significant multicollinearity of the independent variables. Univariate and multivariable negative binomial regression was performed with count of emergency admissions for asthma as the dependent variable, and each individual and composite measure of access as the main independent variable. These were adjusted for potential confounders (list size, rank of IMD, QOF indicator Asthma 6, QOF indicator Asthma 8, rank of proportion of white population, percentage of practice population who were female, average age of practice population, and distance from nearest hospital), weighted for practice size and clustered at primary care trust level. Results are presented as incidence rate ratios (IRR) with $95 \%$ confidence intervals.

\section{RESULTS}

In total, 7806 (95\%) of 8236 general practices had complete datasets for all variables (Table 1). In these practices there were 3134106 patients with asthma, and there were 55570 emergency admissions. A scatterplot displays the emergency admissions for asthma and composite scores for practices (Figure 1). The median rate of admissions per 1000 asthma patients was 16 (IQR 9-26, range 0-700). The median 
Table 2. Incidence rate ratio for individual and composite questions

\begin{tabular}{|c|c|c|c|c|c|c|c|c|c|c|c|}
\hline \multirow[b]{2}{*}{ Access variable } & \multicolumn{4}{|c|}{$\begin{array}{c}\text { Unadjusted ( } 10 \% \text { increase in } \\
\text { access variable) }\end{array}$} & \multicolumn{4}{|c|}{$\begin{array}{c}\text { Adjusted }{ }^{\mathrm{a}} \text { ( } 10 \% \text { increase in } \\
\text { access variable) }\end{array}$} & \multicolumn{3}{|c|}{$\begin{array}{l}\text { Change in admissions for } 10 \% \\
\text { increase in access variable }\end{array}$} \\
\hline & IRR & $95 \% \mathrm{LCI}$ & $95 \% \mathrm{UCl}$ & $P$-value & IRR & $95 \% \mathrm{LCl}$ & $95 \% \mathrm{UCl}$ & $P$-value & $\%$ change & $95 \% \mathrm{LCl}$ & $95 \% \mathrm{UCl}$ \\
\hline $\begin{array}{l}\text { Q1: How easy have } \\
\text { you found getting } \\
\text { through on } \\
\text { the phone? }(\%)\end{array}$ & 0.975 & 0.957 & 0.995 & 0.016 & 0.980 & 0.961 & 1.000 & 0.102 & -2.0 & -3.9 & 0.0 \\
\hline $\begin{array}{l}\text { Q2: Are you able } \\
\text { to see doctor in } \\
2 \text { days? }(\%)\end{array}$ & 0.988 & 0.964 & 1.014 & 0.360 & 0.997 & 0.973 & 1.020 & 0.813 & -0.3 & -2.7 & 2.0 \\
\hline $\begin{array}{l}\text { Q3: Are you able } \\
\text { to book ahead? (\%) }\end{array}$ & 0.978 & 0.963 & 0.994 & 0.008 & 0.990 & 0.970 & 1.000 & 0.065 & -1.0 & -3.0 & 0.0 \\
\hline $\begin{array}{l}\text { Q4: Can patients } \\
\text { overhear in } \\
\text { reception? }(\%)\end{array}$ & 1.013 & 0.986 & 1.040 & 0.354 & 1.007 & 0.980 & 1.030 & 0.567 & 0.7 & -2.0 & 3.0 \\
\hline $\begin{array}{l}\text { Q6: See their } \\
\text { preferred doctor } \\
\text { always, almost } \\
\text { always, or a lot of } \\
\text { the time }(\%)\end{array}$ & 0.996 & 0.975 & 1.016 & 0.695 & 1.010 & 0.990 & 1.030 & 0.513 & 1.0 & -1.0 & 3.0 \\
\hline $\begin{array}{l}\text { Q7: Ease getting } \\
\text { appointment with } \\
\text { practice nurse (\%) }\end{array}$ & 1.010 & 0.990 & 1.041 & 0.313 & 1.030 & 1.000 & 1.051 & 0.041 & 3.0 & 0.0 & 5.1 \\
\hline $\begin{array}{l}\text { Composite access } \\
\text { variable }\end{array}$ & 0.675 & 0.652 & 0.700 & $<0.001$ & 0.679 & 0.665 & 0.708 & $<0.0001$ & -32.1 & -33.5 & -29.2 \\
\hline
\end{tabular}

composite access score was $72.07 \%$ (IQR 66.38-77.02\%). Table 2 displays the main results for the composite access indicator and the seven individual access questions. In the unadjusted analysis Q1 (being able to get through on the phone), Q3 (are you able to book ahead), and the composite access variable were associated with statistically significantly lower emergency admissions for asthma. In the adjusted model the composite access variable was statistically significantly associated with lower emergency admissions for asthma. Based on the adjusted model, a 10\% increase in access measured by the composite variable would be associated with a $32.1 \%$ reduction in emergency admissions for asthma. Emergency admissions for asthma were higher in practices with lower composite access scores (IRR 0.96, $P<0.001$ ), higher proportions of the practice population who were white (IRR 1.00, $P=0.008$ ), and in practices with lower performance in QOF quality indicator asthma review in past 15 months' (IRR 0.99, P<0.001) (Appendix 2). Re-analysis of the data adjusting for response rates for the GP practice survey, and excluding possible influential outliers Ithose practices with admission rates of more than 200 per 1000 population per year), did not significantly change these findings (IRR for the composite outcome $0.677,95 \% \mathrm{Cl}=0.657$ to $0.698, P<0.0001)$. An increase in composite access scores of $10 \%$ was associated with a decrease in 17837 emergency admissions for asthma, which is approximately two less emergency admissions for every practice in the year.

\section{DISCUSSION}

\section{Summary}

General practices with higher access scores to primary care for the composite measures had fewer emergency admissions for asthma. A $10 \%$ higher access score is associated with a $32.1 \%$ decrease in emergency asthma admissions and this is clinically important, as emergency attendance at hospital with asthma is a significant risk factor for mortality. ${ }^{4}$ An association between admission rates and ethnic group was expected, as these findings have been reported by others examining variations in total emergency 
admissions. ${ }^{31,32}$ Emergency admissions were lower in practices with higher performance in quality indicator asthma review in past 15 months' (Asthma 6), but were not associated with performance in quality indicator asthma patients with measures of variability or reversibility (Asthma 8). Although each individual access question was not statistically associated with admission rates when adjusted for potential explanatory variables, the composite indicator that measures the overall access to the practice was substantially associated with admission rates.

\section{Strengths and limitations}

Strengths of this study include a large survey sample including 95\% of English practices and adjustment of data for sociodemographic characteristics of practices. The patient access data were based on a large survey of $10 \%$ of the practice population with a response rate of $41 \%$ in these practices. It is the first study to use a composite measure of access.

There are limitations to this type of study. The data are cross-sectional and therefore longitudinal inferences cannot be made. This is an observational study and as such it does not demonstrate causation, and because it is an ecological (area-based) study, associations at the practice level may not apply to individuals. There may be other variables omitted from the model that may explain admission rates. The GP Patient Survey may not include all elements relative to patient access to practices, and is based on retrospective recall of patients. QOF scores may not capture the most important elements of asthma care, and higher scores may reflect better practice organisation rather than quality of care. There is potential for significant associations between the independent variables that may confound the findings, but adjustments were made for several potential confounders. One measure accounting for $2.7 \%$ of the IMD score is emergency admissions, and asthma makes up $1.2 \%$ of emergency admissions in 2010 . This raises the potential for endogeneity between the IMD score and the dependent variable. This does not appear to be a problem as there is only a weak correlation between emergency admissions for asthma and all emergency admissions (correlation coefficient 0.20), and emergency admissions for asthma only account for a very small proportion (0.0003) of the total IMD score.

\section{Comparison with existing literature}

This national study concurs with the findings of the National Review of Asthma Deaths and two further studies in which interventions to increase access were associated with reduced emergency admissions.4,12,13 This study contrasts with the findings of other research that reported decreased emergency admission with increasing distance from hospital and with higher deprivation. ${ }^{31-33}$ The study differs from those in that a multilevel analysis was used clustering at the primary care trust level. The study concurs with others that reported increased emergency admissions with an increasing proportion of the population who are white. ${ }^{31,32}$ It also adds to the literature finding an association between increasing access to primary care and decreasing emergency admissions for other conditions. ${ }^{18-23}$ The findings that some QOF indicators may not be related to outcome measures of care have also been reported in other studies examining emergency admissions ${ }^{31,32}$ and premature mortality. ${ }^{34}$ The study contrasts with an earlier study of all English practices that found emergency asthma admissions were higher in practices with a lower recording of diagnosis of asthma by spirometry. ${ }^{33}$

\section{Implications for research}

This is the first study examining the relationship between emergency admissions with asthma and measures of access to primary care at a national level, and the first to use the composite access score. A longitudinal study of emergency admissions for asthma and its relationship to changes in reported access for primary care is required to validate the findings of this cross-sectional study. It was found that a quality indicator asthma review in past 15 months' was associated with decreased emergency asthma admissions, although this has since been dropped from the QOF. Conversely, quality indicator 'asthma patients with measures of variability or reversibility' was not associated with a reduction in asthma admissions, although it remains in the QOF in a revised form. This large observational study adds to the weight of evidence that good access to primary care is associated with fewer hospital admissions, and policymakers may wish to consider how and where to improve access.

\section{providing the data for this study.} Care Information Centre for their help in

\section{Discuss this article}

Contribute and read comments about this article: bjgp.org/letters 


\section{REFERENCES}

1. Health and Social Care Information Centre. Quality and Outcomes Framework (QOF) 2013-14: prevalence, achievements and exceptions at region and nation level for England. Leeds: HSCIC, 2014. http://www.hscic.gov.uk/catalogue/ PUB15751 (accessed 13 Jun 2016).

2. British Thoracic Society, Scottish Intercollegiate Guidelines Network. British guideline on the management of asthma. SIGN 141. Edinburgh: SIGN, 2014. http://www.sign.ac.uk/pdf/SIGN141.pdf (accessed 13 Jun 2016).

3. Department of Health. Quality and Outcomes Framework 2011-2012. Leeds: HSCIC, 2012. http://www.hscic.gov.uk/catalogue/PUB08135 laccessed 13 Jun 2016).

4. Levy ML, Andrews R, Buckingham R, et al. Why asthma still kills: the National Review of Asthma Deaths (NRAD). London: RCP, 2014. https://www.rcplondon. ac.uk/projects/outputs/why-asthma-still-kills (accessed 13 Jun 2016).

5. Information Centre for Health and Social Care. Indicator construction: managing emergency admissions. Leeds: Information Centre for Health and Social Care, 2013. wnw.productivity.nhs.uk/Download/TechnicalDefinition/608 laccessed 13 Jun 2016).

6. Agency for Healthcare Research and Quality. Prevention quality indicators technical specifications, version 4.4, March 2012. http://www.qualityindicators. ahrq.gov/Archive/PQI_TechSpec_V44.aspx (accessed 13 Jun 2016).

7. Rabe KF, Adachi M, Lai CK, et al. Worldwide severity and control of asthma in children and adults: the global asthma insights and reality surveys. J Allergy Clin Immunol 2004, 114(1): 40-47.

8. Huntley A, Lasserson D, Wye L, et al. Which features of primary care affect unscheduled secondary care use? A systematic review. BMJ Open 2014; 4(5): e004746.

9. Department of Health, Respiratory Team. An outcomes strategy for chronic obstructive pulmonary disease (COPD) and asthma in England. London: DH, 2011. https://www.gov.uk/government/uploads/system/uploads/attachment_ data/file/216139/dh_128428.pdf laccessed 13 Jun 2016).

10. Bhogal SK, McGillivray D, Bourbeau J, et al. Early administration of systemic corticosteroids reduces hospital admission rates for children with moderate and severe asthma exacerbation. Ann Emerg Med 2012; 60(1): 84-91 e83.

11. Griffiths C, Foster $G$, Barnes N, et al. Specialist nurse intervention to reduce unscheduled asthma care in a deprived multiethnic area: the east London randomised controlled trial for high risk asthma (ELECTRA). BMJ 2004 328(7432): 144

12. Smith JR, Noble MJ, Musgrave $\mathrm{S}$, et al. The at-risk registers in severe asthma (ARRISA) study: a cluster-randomised controlled trial examining effectiveness and costs in primary care. Thorax 2012; 67(12): 1052-1060.

13. Noble MJ, Smith JR, Windley J. A controlled retrospective pilot study of an at-risk asthma register' in primary care. Primary Care Resp J 2006; 15(2): 116-124.

14. Eisner MD, Katz PP, Yelin EH, et al. Risk factors for hospitalization among adults with asthma: the influence of sociodemographic factors and asthma severity. Resp Res 2001; 2(1): 53-60.

15. Campbell J, Smith P, Nissen S, et al. The GP Patient Survey for use in primary care in the National Health Service in the UK - development and psychometric characteristics. BMC Fam Pract 2009; 10: 57.

16. NHS England. The GP Patient Survey January-December 2010 summary report. 2011. http://gp-survey-production.s3.amazonaws.com/archive/2011/ March/unweighted/Mar\%202011\%20National\%20Summary\%20Report.pdf laccessed 13 Jun 2016).
17. Jacobs R, Smith P, Goddard M. Measuring performance: An examination of composite performance indicators. CHE Technical Paper Series 29. York: University of York, 2004. https://www.york.ac.uk/che/pdf/tp29.pdf laccessed 13 Jun 2016).

18. Calderón-Larrañaga A, Carney L, Soljak M, et al. Association of population and primary healthcare factors with hospital admission rates for chronic obstructive pulmonary disease in England: national cross-sectional study. Thorax 2011: 66(3): 191-196.

19. Brettell $R$, Soljak M, Cecil E, et al. Reducing heart failure admission rates in England 2004-2011 are not related to changes in primary care quality: nationa observational study. Eur J Heart Fail 2013; 15(12): 1335-1342

20. Calderón-Larrañaga $A$, Soljak M, Cecil E, et al. Does higher quality of primary healthcare reduce hospital admissions for diabetes complications? A national observational study. Diabet Med 2014; 31(6): 657-665.

21. Soljak M, Calderón-Larrañaga A, Sharma $P$, et al. Does higher quality primary health care reduce stroke admissions? A national cross-sectional study. $\mathrm{Br} \mathrm{J}$ Gen Pract 2011; DOI: 10.3399/bjgp11X613142.

22. Bottle A, Tsang C, Parsons C, et al. Association between patient and general practice characteristics and unplanned first-time admissions for cancer: observational study. Br J Cancer 2012; 107(8): 1213-1219.

23. Calderón-Larrañaga $A$, Soljak M, Cowling TE, et al. Association of primary care factors with hospital admissions for epilepsy in England, 2004-2010: national observational study. Seizure 2014; 23(8): 657-661.

24. Zhou Y, Abel G, Warren F, et al. Do difficulties in accessing in-hours primary care predict higher use of out-of-hours GP services? Evidence from an English National Patient Survey. Emerg Med J 2015; 32(5): 373-378.

25. Cowling TE, Harris MJ, Watt HC, et al. Access to general practice and visits to accident and emergency departments in England: cross-sectional analysis of a national patient survey. Br J Gen Pract 2014; DOI: 10.3399/bjgp14X680533.

26. Health and Social Care Information Centre. Indicator portal. 17/05/2012 edn Leeds: NHS, 2014

27. Health Commission. Practice ethnicity data for disease prevalence modelling. Cambridge: Eastern Region Public Health Observatory, 2010.

28. Sizmur S. Composite domain markers for GPS. Oxford: Picker Institute Europe; 2012.

29. Campbell JL, Carter M, Davey A, et al. Accessing primary care: a simulated patient study. Br J Gen Pract 2013, DOI: 10.3399/bjgp13X664216.

30. Department for Communities and Local Government. The English Indices of Deprivation 2010. London: DCLG, 2011. https://www.gov.uk/government/ uploads/system/uploads/attachment_data/file/6871/1871208.pdf laccessed 25 May 2016).

31. Gunther S, Taub N, Rogers S, Baker R. What aspects of primary care predict emergency admission rates? A cross sectional study. BMC Health Serv Res 2013; 13: 11.

32. Bankart MJ, Baker R, Rashid A, et al. Characteristics of general practices associated with emergency admission rates to hospital: a cross-sectional study. Emerg Med J 2011; 28(7): 558-563.

33. Purdy S, Griffin T, Salisbury C, Sharp D. Emergency respiratory admissions: influence of practice, population and hospital factors. J Health Serv Res Policy 2011; 16(3): 133-140.

34. Kontopantelis E, Springate DA, Ashworth M, et al. Investigating the relationship between quality of primary care and premature mortality in England: a spatial whole-population study. BMJ 2015; 350: h904. 


\section{Appendix 1. Composite 'accessing care' indicator (source: Picker Institute $)^{28}$}

This composite indicator is a combination of the following seven questions taken from the GP Patient Survey data, with equal weighting for each question, reported on a scale of 0-10.

Q1 In the past 6 months, how easy have you found getting through on the phone?

Q2 Think about the last time you tried to see a doctor fairly quickly. Were you able to see a doctor on the same day or in the next 2 weekdays the GP surgery or health centre was open?

Q3 Last time you tried to, were you able to get an appointment with a doctor more than 2 full weekdays in advance?

Q4 In the reception area, can other patients overhear what you say to the receptionist?

Q5 How helpful do you find the receptionists at your GP surgery or health centre?

Q6 How often do you see the doctor you prefer to see?

Q7 How easy is it for you to get an appointment with a practice nurse at your GP surgery or health centre?

\section{Appendix 2. Full regression model}

\begin{tabular}{|c|c|c|c|c|c|}
\hline & IRR & $\begin{array}{l}\text { Standard } \\
\text { error }\end{array}$ & $z$ & $P$-values & $95 \% \mathrm{Cl}$ \\
\hline$\%$ Composite access score & 0.962862 & 0.001558 & -23.39 & $<0.001$ & 0.959813 to 0.96592 \\
\hline Average age, years & 0.989058 & 0.003703 & -2.94 & 0.003 & 0.981827 to 0.996341 \\
\hline$\%$ Female & 1.047712 & 0.007683 & 6.36 & $<0.001$ & 1.032762 to 1.062878 \\
\hline $\begin{array}{l}\text { Rank, proportion of } \\
\text { population who were white }\end{array}$ & 1.000025 & $9.23 \mathrm{E}-06$ & 2.65 & 0.008 & 1.000006 to 1.000043 \\
\hline Rank IMD 2010 score & 1.000001 & 8.06E-06 & 0.12 & 0.907 & 0.999985 to 1.000017 \\
\hline $\begin{array}{l}\% \text { Achievement Asthma } 6 \\
\text { lasthma review within } 15 \text { mor }\end{array}$ & $\begin{array}{l}0.99354 \\
\text { ths) }\end{array}$ & 0.001528 & -4.22 & $<0.001$ & 0.990551 to 0.996539 \\
\hline $\begin{array}{l}\% \text { Achievement Asthma } 8 \\
\text { (measures of variability or } \\
\text { reversibility) }\end{array}$ & 0.997757 & 0.001498 & -1.5 & 0.135 & 0.994825 to 1.000698 \\
\hline $\begin{array}{l}\text { Distance to nearest } \\
\text { hospital, } \mathrm{km}\end{array}$ & 1.001424 & 0.001873 & 0.76 & 0.447 & 0.99776 to 1.005102 \\
\hline \multicolumn{6}{|c|}{$\begin{array}{l}\text { Dependent variable: the rate of emergency admissions for asthma per } 1000 \text { patients on the asthma register. } \\
\text { Weighted for practice size and clustered at the primary care trust level. IRR = incidence rate ratio. IMD = Index of }\end{array}$} \\
\hline
\end{tabular}

